\title{
Síndrome pulmonar por hantavirus en población infantil. Chile: Regiones IX y X. 1998-2000
}

\author{
GUILLERMO SOZA C. ${ }^{1}$, PEDRO LORCA O.${ }^{1}$, SERGIO PUEBLA M.${ }^{1}$, MARISOL WENZEL M.${ }^{2}$, \\ MARITZA NAVARRETE C. ${ }^{3}$, ELIECER VILLAGRA C. ${ }^{4}$, JUDITH MORA R. ${ }^{4}$, \\ SILVANA LEVIS C. ${ }^{5}$ y GABRIELA AVILES A. ${ }^{5}$
}

\section{HANTAVIRUS PULMONARY SYNDROME IN CHILDREN. CHILE: IX AND X REGIONS, 1998-2000}

Hantavirus Pulmonary Syndrome (HPS) has been present in Chile since 1993 and it was first detected during 1997 in our region. It is a particularly serious zoonosis with a high mortality rate that affects young people including children. We refer our experience with 6 pediatric patients admitted into the Intensive Care and Pediatric Isolation units at Hospital Regional de Temuco (January 1998 to January 2000) including a description of our experience assisting these patients based on information obtained from clinical files and epidemiological visits. The hantavirus infection was confirmed by positive specific IgM and IgG ELISA tests. Search of viral genome was done by RT-PCR. The average age was 6 yrs $-5 \mathrm{~ms}$ (range: 2-10 yrs). The ratio of male/females was 4/2. The origin of the patients was: rural areas near the Andes Mountains (n: 4) and rural coast (n: 2). The exposure to infection was in uninhabited houses or barns. The average incubation period was: 14 days (range: 7-21). The symptoms were: high fever, intense abdominal pain, vomiting, myalgias, clinical and Rx respiratory distress in all. The main hematological findings were: thrombocytopenia, high leukocytes count, immunoblasts and atypical lymphocytic cells. All cases were confirmed by IgM and IgG positive tests. The Andes virus genomic sequence was found in blood of one pediatric patient and in his uncle. Two patients who required mechanical ventilation and shock management finally died, the other patients recovered rapidly. Hantavirus Pulmonary Syndrome has no specific treatment. Prevention, an opportune diagnostic suspicion and aggressive treatment are the current strategies to control this disease.

Key words: Hantavirus Pulmonary Syndrome, Pediatric disease, Chilean experience.

\section{INTRODUCCION}

\footnotetext{
1 Servicio de Pediatría. Unidad de Cuidados Intensivos y Aislamiento. Hospital Regional Temuco. IX Región.

Servicio de Pediatría. Hospital Clínico Valdivia. X Región.

3 Instituto de Microbiología Clínica. Universidad Austral de Chile.

4 Instituto de Salud Pública de Chile. Sección Virología.

5 Instituto de Enfermedades Virales Julio Maiztegui. Pergamino, Buenos Aires-Argentina.
} 
El síndrome pulmonar por hantavirus $(\mathrm{SPH})$ se inscribe en el grupo de enfermedades probablemente reemergentes. Fue descrito en Chile desde 1995, sin embargo, estudios retrospectivos confirman la existencia de esta patología desde 1993

(artículo relacionado de M. Navarrete et al, pág: 233).

En la IX Región del país se ha detectado a partir de 1997.1-3

El agente viral es portado por ratones de campo que lo transmiten accidentalmente al ser humano. Es por lo tanto una zoonosis, con características de particular gravedad por su elevada letalidad, que se proyecta epidemiológicamente como endemia en el futuro. ${ }^{4}$

Afecta especialmente a gente joven incluyendo niños. Los reportes de presentación clínica en la población infantil son escasos. ${ }^{5,6}$ Como una forma de contribuir al conocimiento de esta nueva y dramática entidad clínica, nos parece oportuno dar a conocer nuestra experiencia en pacientes pediátricos con SPH de las regiones IX y X del país.

\section{Objetivos}

- Dar a conocer aspectos epidemiológicos, clínicos, evolutivos y de manejo terapéutico en 6 pacientes pediátricos con cuadro clínico confirmado de SPH.

- Retroalimentar la capacidad diagnóstica y resolutiva del equipo de salud, reforzando las medidas de vigilancia epidemiológica y oportuno diagnóstico.

- Obtener la información necesaria para optimizar el manejo terapéutico del SPH.

\section{MATERIAL Y METODO}

Estudio descriptivo de la experiencia del equipo de salud en el manejo clínico de 6 pacientes pediátricos con diagnóstico confirmado de $\mathrm{SPH}$ que se presentaron en las Regiones IX y X del país, entre enero de 1998 y febrero de 2000.

La información clínico-epidemiológica fue extraída de registros, fichas clínicas y visitas epidemiológicas.

Confirmación etiológica y análisis virológico:

- Estudio serológico de anticuerpos antihantavirus: IgM por técnica de ELISA de captura empleando como antígeno virus Laguna Negra e IgG por ELISA usando como antígeno Virus sin Nombre realizadas en el ISP de Chile e Instituto de Microbiología, U. Austral de Chile. Los antígenos fueron proporcionados por el CDC, Atlanta, E.U.A.

- Detección de genoma viral de hantavirus en muestras de sangre: amplificación mediante transcriptasa-reversa y reacción de polimerasa en cadena (TR-RPC) efectuadas en el Instituto de Enfermedades Virales Julio Maiztegui, Pergamino, Buenos Aires, Argentina. ${ }^{7-9}$

\section{RESULTADOS}

Antecedentes epidemiológicos. El promedio de edad fue de 6 años 9 meses (rango: 2 años 5 meses a 10 años). Predominio en sexo masculino (H/M: 2/1) (Tabla 1).

El mayor número de pacientes se presentó en 1998, con una distribución estacional en verano y otoño. La mayoría (n: 4) procedía del sector cordillerano de la IX Región y el resto (n: 2) de la zona costera de Valdivia en la X Región.

En 2 pacientes hubo otro enfermo con SPH en el grupo familiar (ver casos clínicos).

En todos los enfermos se obtuvo el antecedente de permanencia en bodegas, galpones o casas deshabitadas de zona rural. En 4 pacientes la familia vive en el lugar donde realizaban labores agrícolas, en los otros 2 su permanencia fue por motivos recreacionales (vacaciones).

El período promedio de incubación fue de 14 días (rango: 7-20 días).

Aspectos clínicos. El comienzo se caracterizó en todos los enfermos por ser agudo con fiebre elevada $\left(38-40^{\circ} \mathrm{C}\right)$ y mantenida tanto en la fase prodrómica como en la fase pulmonar. El dolor abdominal estuvo presente en forma constante en todos los pacientes, en 3 fue de tanta intensidad que hizo sospechar un cuadro de abdomen agudo. Este síntoma se inició entre 
el $3^{\circ}$ y $4^{\circ}$ día de la fase prodrómica y se extendió a la fase pulmonar en 4 de 6 pacientes, en 5 a 7 días. Las mialgias, especialmente en las extremidades inferiores, tuvieron un paralelismo en intensidad y duración con los dolores abdominales y se presentaron en todos los enfermos. Los vómitos y cefalea fueron constantes en la fase prodrómica, de mediana a gran intensidad. En 5 de 6 pacientes se detectó hepatomegalia de mediano a gran tamaño y esplenomegalia moderada (Tabla 2).

Todos los pacientes tuvieron compromiso respiratorio. En la fase prodrómica sólo 2 relataron odinofagia y otalgia. Dos pacientes tuvieron un compromiso pulmonar moderado, 4 de intensidad mediana a severa, de los cuales fallecieron dos. La tos, polipnea y dificultad respiratoria, tuvieron un paralelismo con los hallazgos en la radiografía de tórax. Los casos graves mostraron un patrón característico del síndrome de distress respiratorio de tipo adulto en niños (ver casos clínicos).

Exámenes de laboratorio (Tabla 3). Todos los pacientes tuvieron leucocitosis y neutrofilia. El valor promedio de glóbulos blancos fue $36.000 / \mathrm{mm}^{3}$ (rango 10.000 a 46.000 ). Este au- mento fue a expensas de neutrófilos y formas inmaduras, excepto en un paciente en el cual se presentó una gran linfocitosis con formas atípicas que sugirió un trastorno linfoproliferativo. Estos hallazgos fueron detectados en la fase final del período prodrómico y de presencia mantenida en la fase de compromiso pulmonar. El hematocrito elevado en 4 de 6 pacientes tuvo una relación estricta con la gravedad del compromiso pulmonar, alcanzando los valores más elevados en los casos fatales. Debe destacarse que todos los enfermos presentaron trombocitopenia. Esta alteración se detectó antes de la fase pulmonar y aunque no tuvo una relación estrecha con la gravedad, su normalización fue paralela a la mejoría del cuadro respiratorio.

Los valores de PCR fueron bajos $(\mathrm{VN}<30$ $\mathrm{mg} / \mathrm{l})$.

Todos los pacientes tuvieron alza de transaminasas hepáticas (GOT-GPT), sin paralelismo con la gravedad del cuadro. Los valores promedio fueron GOT: $278 \mathrm{U} / 1$ (VN: 10-40) y GPT: 118 U/l (VN: 10-40). Se detectaron elevadas al inicio de la fase pulmonar, normalizándose en la primera semana.

En 3 pacientes se detectó aumento de la enzi-

Tabla 1. Antecedentes epidemiológicos en 6 pacientes pediátricos con síndrome pulmonar por hantavirus. Chile 1998-2000

\begin{tabular}{|c|c|c|c|c|c|c|}
\hline & Paciente 1 & Paciente 2 & Paciente 3 & Paciente 4 & Paciente 5 & Paciente 6 \\
\hline $\begin{array}{l}\text { Estación } \\
\text { climática } \\
\text { y año }\end{array}$ & $\begin{array}{c}\text { Verano } \\
1998\end{array}$ & $\begin{array}{c}\text { Verano } \\
1998\end{array}$ & $\begin{array}{c}\text { Otoño } \\
1998\end{array}$ & $\begin{array}{l}\text { Otoño } \\
1998\end{array}$ & $\begin{array}{c}\text { Verano } \\
1999\end{array}$ & $\begin{array}{c}\text { Verano } \\
2000\end{array}$ \\
\hline $\begin{array}{l}\text { Edad } \\
\text { (años/meses) }\end{array}$ & $9 / 0$ & $2 / 5$ & $5 / 6$ & $5 / 1$ & $8 / 0$ & $10 / 4$ \\
\hline Sexo & $\mathrm{F}$ & M & M & M & M & $\mathrm{F}$ \\
\hline Procedencia & $\begin{array}{c}\text { Rural } \\
\text { cordillerano } \\
\text { (Curacautín) }\end{array}$ & $\begin{array}{l}\text { Rural } \\
\text { cordillerano } \\
\text { (Cunco) }\end{array}$ & $\begin{array}{c}\text { Rural } \\
\text { costero } \\
\text { (Valdivia) }\end{array}$ & $\begin{array}{c}\text { Rural } \\
\text { cordillerano } \\
\text { (Villarrica) }\end{array}$ & $\begin{array}{c}\text { Rural } \\
\text { costero } \\
\text { (Valdivia) }\end{array}$ & $\begin{array}{c}\text { Rural } \\
\text { cordillerano } \\
\text { (Curacautín) }\end{array}$ \\
\hline $\begin{array}{l}\text { Posible lugar } \\
\text { de contagio }\end{array}$ & $\begin{array}{c}\text { Casa } \\
\text { deshabitada }\end{array}$ & $\begin{array}{c}\text { Casa } \\
\text { deshabitada }\end{array}$ & $\begin{array}{l}\text { Galpón } \\
\text { con paja }\end{array}$ & $\begin{array}{c}\text { Casa } \\
\text { bodega }\end{array}$ & $\begin{array}{c}\text { Casa } \\
\text { bodega }\end{array}$ & $\begin{array}{c}\text { Casa } \\
\text { deshabitada }\end{array}$ \\
\hline $\begin{array}{l}\text { Otro familiar } \\
\text { con SPH }\end{array}$ & & Tío †* & & Padre $\dagger^{*}$ & & \\
\hline $\begin{array}{l}\text { Período de } \\
\text { incubación } \\
\text { (días) }\end{array}$ & 20 & 14 & 7 & \pm 20 & 10 & 15 \\
\hline$* \dagger$ Fallecido. & & & & & & \\
\hline
\end{tabular}


Tabla 2. Hallazgos clínicos relevantes en 6 pacientes pediátricos con síndrome pulmonar por hantavirus. Chile 1998-2000

\begin{tabular}{|c|c|c|c|c|c|c|}
\hline & Paciente 1 & Paciente 2 & Paciente 3 & Paciente 4 & Paciente 5 & Paciente 6 \\
\hline Fiebre $\left({ }^{\circ} \mathrm{C}\right)$ & $39-40$ & $39-40$ & $38-39$ & $>40$ & $39-40$ & $39-40$ \\
\hline Vómitos & +++ & ++ & +++ & +++ & ++++ & +++ \\
\hline Cefalea & ++ & + & ++ & ++ & +++ & ++ \\
\hline Dolor abdominal & ++++ & ++ & ++++ & +++ & ++++ & +++ \\
\hline Mialgias & ++++ & ++ & +++ & ++++ & +++ & ++ \\
\hline Hepatomegalia & +++ & ++ & +++ & + & ++ & ++++ \\
\hline Esplenomegalia & + & + & ++ & + & + & ++ \\
\hline Tos & +++ & ++ & +++ & +++ & +++ & +++ \\
\hline Polipnea & +++ & ++ & +++ & ++++ & +++ & ++++ \\
\hline SDRA* & +++ & + & +++ & ++++ & +++ & ++++ \\
\hline Shock & No & No & No & Sí & No & $\mathrm{Si}$ \\
\hline Resolución & $\mathrm{S}$ & $\mathrm{S}$ & $\mathrm{S}$ & $\dagger$ & $\mathrm{S}$ & $\dagger$ \\
\hline
\end{tabular}

Tabla 3. Exámenes de laboratorio en 6 pacientes pediátricos con síndrome pulmonar por hantavirus. Chile 1998-2000

\begin{tabular}{|c|c|c|c|c|c|c|}
\hline & Paciente 1 & Paciente 2 & Paciente 3 & Paciente 4 & Paciente 5 & Paciente 6 \\
\hline \multicolumn{7}{|l|}{ Hemograma } \\
\hline Leucocitos $/ \mathrm{mm}^{3}$ & 10.900 & 46.000 & 42.000 & 45.000 & 26.000 & 36.000 \\
\hline - Baciliformes (\%) & 4 & 14 & 3 & 5 & 10 & - \\
\hline • Neutrófilos (\%) & 74 & 26 & 76 & 78 & 58 & 72 \\
\hline - Linfocitos $(\%)$ & 16 & 60 & 7 & 13 & 25 & 20 \\
\hline Hematocrito (\%) & 44 & 29,3 & 43,2 & 50,6 & 33,7 & 57,1 \\
\hline Plaquetas $/ \mathrm{mm}^{3}$ & 57.000 & 67.000 & 45.000 & 56.000 & 32.000 & 54.000 \\
\hline \multicolumn{7}{|l|}{ Bioquímica } \\
\hline PCR (mg/l) & 10 & 7,6 & 6 & 18 & 34 & s/d \\
\hline GOT (U/l) & 154 & 621 & 187 & 299 & 390 & 15 \\
\hline GPT (U/l) & 78 & 239 & 42 & 85 & 208 & 56 \\
\hline DHL (U/l) & 638 & $\mathrm{~s} / \mathrm{d}$ & 997 & s/d & 1.791 & $\mathrm{~s} / \mathrm{d}$ \\
\hline Creatininemia (mg\%) & 0,5 & 0,4 & 0,4 & 0,5 & 1,1 & 1,2 \\
\hline \multicolumn{7}{|c|}{ Electrolitos plasmáticos } \\
\hline $\mathrm{Na}(\mathrm{mEq} / \mathrm{l})$ & 115,0 & 131,0 & 118,0 & 127,0 & 123,0 & 133,0 \\
\hline $\mathrm{K}(\mathrm{mEq} / \mathrm{l})$ & 6,2 & 5 & 4,5 & 3,9 & 4,5 & 5,7 \\
\hline Serología hantavirus & s $1^{\circ} 2^{\circ}$ & $1^{\circ} \quad 2^{\circ}$ & $1^{\circ} \quad 2^{\circ}$ & $1^{\circ} \quad 2^{\circ}$ & $1^{\circ} \quad 2^{\circ}$ & $1^{\circ} \quad 2^{\circ}$ \\
\hline IgM & $(+)(+)$ & $(+)(+)$ & $(+)(+)$ & $(-) \quad(+)$ & $(+)(+)$ & $(+) \quad(-)$ \\
\hline IgG & $(+)(+)$ & $(+)(+)$ & $(+)(+)$ & $(-) \quad(+)$ & $(-) \quad(+)$ & $(+) \quad(-)$ \\
\hline
\end{tabular}


ma deshidrogenasa láctica. En los 2 casos fatales no fue posible medir esta enzima (VN: 230$460 \mathrm{U} / 1)$.

Las cifras de creatininemia fueron normales en 4 pacientes y en el límite alto en 2, uno de ellos fallecidos.

Todos los enfermos cursaron con hiponatremia (promedio: $124,5 \mathrm{mEq} / \mathrm{l}$ ), sin paralelismo con la gravedad. En un enfermo hubo un aumento transitorio de sodio urinario en la fase de convalecencia con valores de creatinina normales. Dos pacientes presentaron hipoalbuminemia.

\section{Confirmación etiológica y estudios virológicos}

Todos los pacientes presentaron serología positiva para $\operatorname{IgM}$ e IgG específica para hantavirus en una o dos determinaciones (Tabla 3 ).

En las muestras del coágulo sanguíneo de los pacientes pediátricos y familiares adultos fallecidos, se realizó pesquisa del genoma viral por TR-RPC. Se detectó material genético viral en dos muestras, una de ellas correspondía a un caso clínico fallecido, (tío del paciente 2), el otro a un paciente pediátrico procedente de Valdivia. Comparando las secuencias nucleotídicas del fragmento de 44 pares de base (pb) del segmento genómico $\mathrm{M}$ obtenidas con regiones homólogas de hantavirus previamente caracterizado, se encontró una mayor identidad con el virus Andes (98\%) y en menor grado con otros hantavirus americanos. Se concluyó que la infección se produjo con cepas de virus Andes.

Se describen a continuación dos casos clínicos pertenecientes a grupos familiares con más de un enfermo.

Caso 1. (Paciente 2). Sexo masculino. Edad: 2 años 5 meses. El 01-02-98 la familia ocupó una casa de verano, deshabitada, en sector rural cordillerano cercano a la localidad de Cunco. (Figura 1). El 15-02-98 presentó fiebre elevada, anorexia, dolor abdominal, vómitos, compromiso general. Visto por médico en Temuco (20-02-98) solicitó hemograma que revelaba 46.000 leucocitos $/ \mathrm{mm}^{3}$ a expensas de linfocitosis, con formas inmaduras. Plaquetas disminuidas: $67.000 / \mathrm{mm}^{3}$. Triglicéridos aumentados en sangre. (900 mg\%). Se internó en el Hospital Regional de Temuco para descartar una enfermedad hematológica. Un mielograma descartó una leucemia, apreciándose actividad megacariocítica. El 21-02-98 presentó tos y dificultad respiratoria leve. La radiografía de

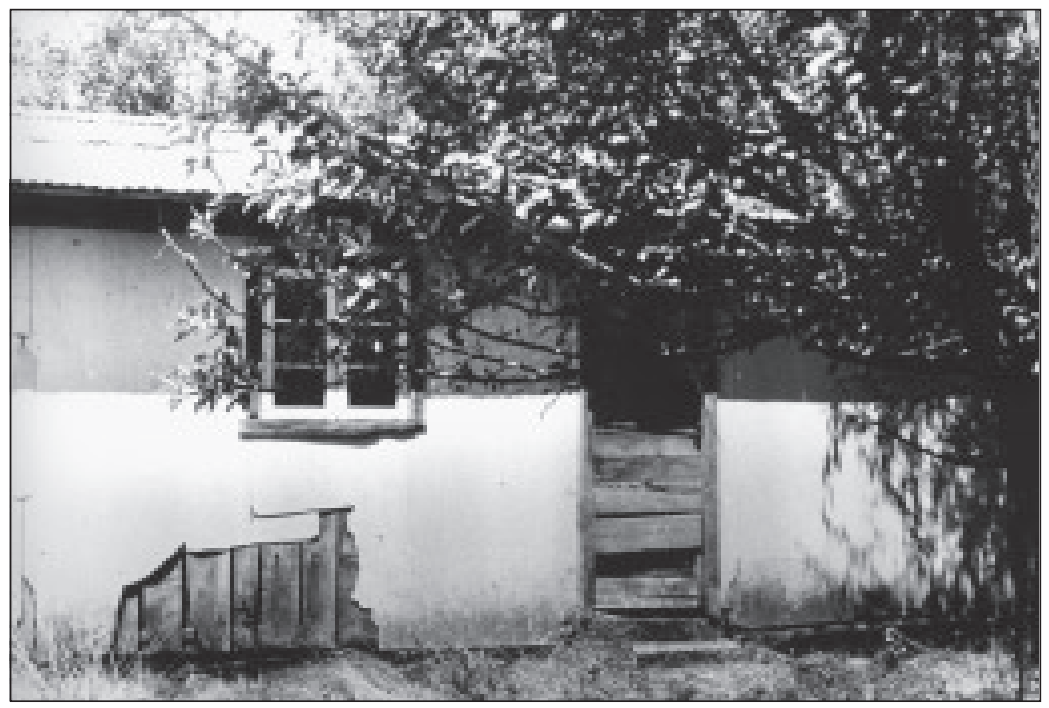

Figura 1. Casa deshabitada. Probable fuente de contagio para el paciente 2. 


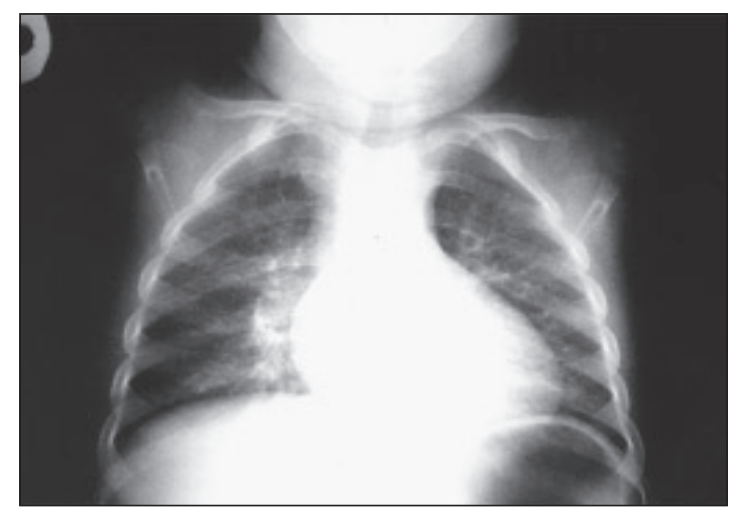

Figura 2. Radiografía de tórax. Paciente 2. (Ver texto).

tórax reveló múltiples infiltrados de aspecto mixto con predominio en las regiones perihiliares de ambos pulmones y mayor confluencia en base del pulmón derecho. Cisura de lóbulo medio acentuada (Figura 2).

Se sospechó $\mathrm{SPH}$ por razones epidemiológicas y clínicas, permanencia en zona rural, dolor abdominal, neumonitis intersticial y las alteraciones hematológicas descritas. Se confirmó por serología $\operatorname{IgM}$ e $\operatorname{IgG}(+)$ para hantavirus (2602-98).

La evolución fue satisfactoria. La fiebre se prolongó por 4 días, el compromiso respiratorio (polipnea y tos) cedió al cabo de una semana y el dolor abdominal disminuyó progresivamente en 4 a 5 días. En el control radiográfico (05-03-98) se apreciaban lesiones residuales mínimas.

El 13-03-98 un tío paterno con 26 años de edad, con el cual estuvo en contacto entre el 10 y 20 de Febrero, falleció por un cuadro fulminante de SPH. En la Figura 3 se aprecian las características de la radiografía de tórax.

Caso 2. (Paciente 4). Sexo masculino, 5 años 1 mes. Procedencia: Fundo "El Libanés" cercano a ciudad de Villarrica, sector rural pre cordillerano. El 22-03-98 su padre de 25 años falleció por SPH fulminante. El niño lo había acompañado en labores de desmalezamiento de quila y visitó galpones con paja a comienzos de marzo. El 25-03-98 en su condición de contacto se le efectúó serología para hantavirus cuyo resultado fue negativo.

El 10-04-98 presentó cefalea, compromiso

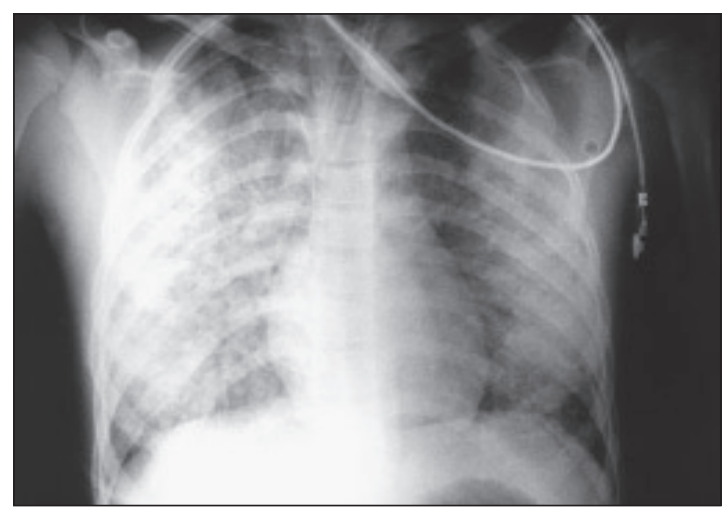

Figura 3. Radiografía de tórax. Paciente tío del paciente 2 (ver texto).

general, el día 11-04 se agregó fiebre sobre $40^{\circ} \mathrm{C}$, dolor abdominal, vómitos frecuentes. El día 13-04 persistían los vómitos, dolor abdominal, fiebre y mialgias generalizadas. Escasa tos. Fue referido a Hospital Regional de Temuco por sospecha de SPH. El 13-04-98, a las 18:00 horas ingresó febril $\left(39,2{ }^{\circ} \mathrm{C}\right)$ sin dificultad respiratoria, con presión arterial de110/70 mmHg y frecuencia cardíaca: $135 \mathrm{ppm}$. Examen pulmonar: murmullo audible, simétrico, con escasas crepitaciones en la base pulmonar derecha. Abdomen con sensibilidad difusa. A las 20:00 horas. una radiografía de tórax mostraba "múltiples imágenes de tipo intersticial y mixtas con cisuritis en el pulmón derecho" (Figura 4). En el hemograma de ingreso el recuento leucocitario fue normal y las plaquetas estaban en el límite inferior. Se indicó iniciar tratamiento con cloxacilina + cefotaxima con

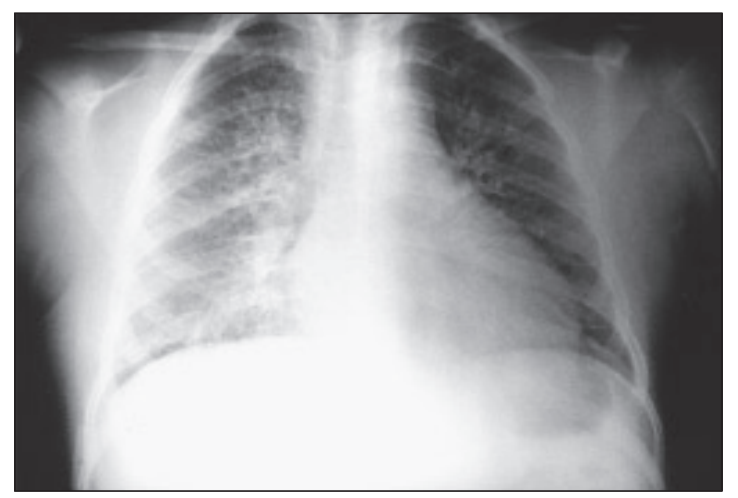

Figura 4. Radiografía de tórax. Paciente 4. (Ver texto). 


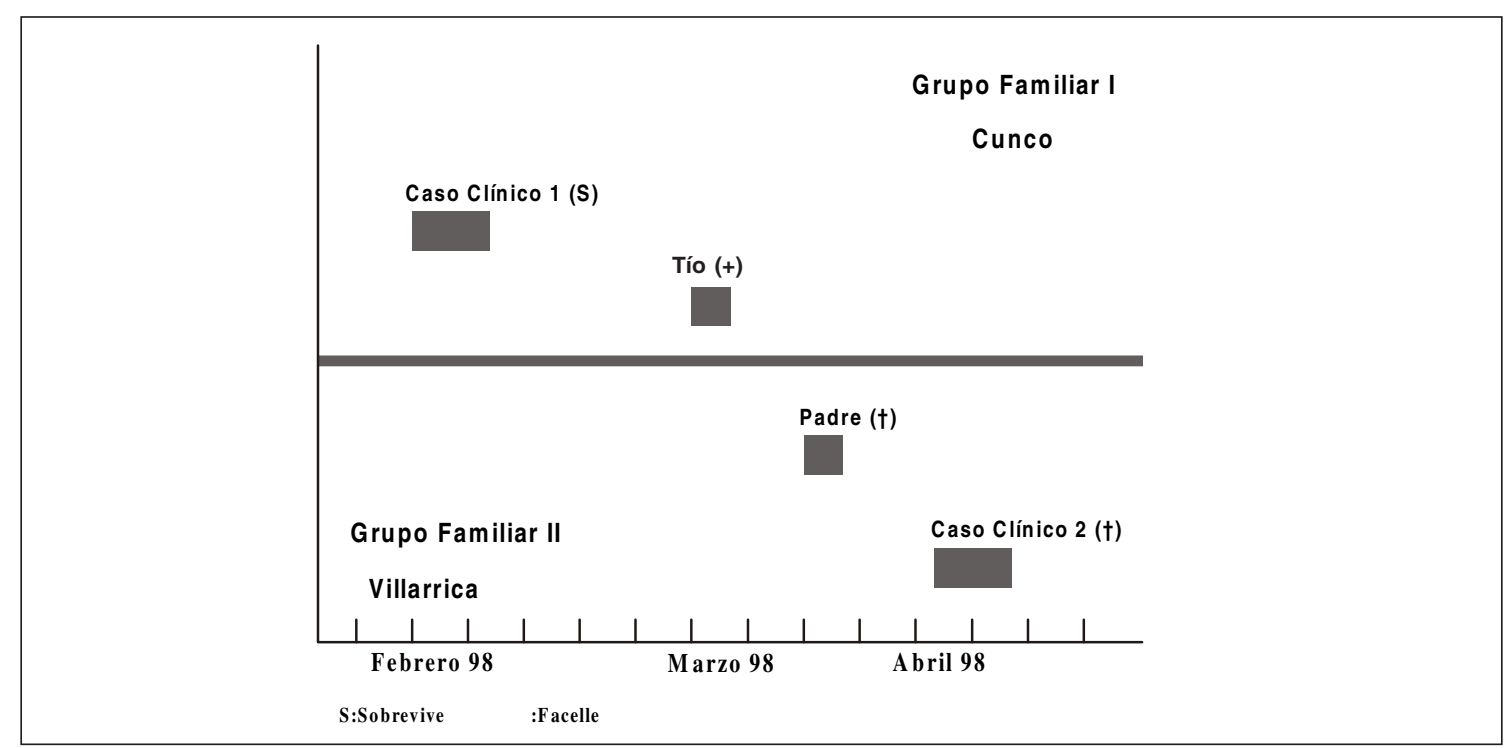

Figura 5. Casos clínicos en brotes (clusters) al interior de grupos familiares.

el diagnóstico de bronconeumonía grave. Se constataron hiponatremia, hipoxemia y acidosis metabólica parcialmente compensada. El día 14-04-98 a las 04:00 horas presentó náuseas y dificultad respiratoria progresiva siendo conectado a ventilación mecánica una hora más tarde. A las 07:00 horas presentó paro cardiorespiratorio del cual se recuperó con maniobras de reanimación. Persistió hipotenso por lo que se instaló catéter venoso central indicándose solución salina fisiológica, dopamina y bicarbonato de sodio. A las 07:15 horas. se apreciaba leve recuperación, con saturación $95 \%$ y presión arterial de 100/60 mm $\mathrm{Hg}$ y pupilas reactivas. Los exámenes de control revelaban gran leucocitosis $\left(45.000 / \mathrm{mm}^{3}\right)$, con neutrofilia, plaquetopenia, hematocrito elevado $(50 \%)$ y acidosis metabólica no compensada con hipoxemia. Posteriormente experimentó nuevo agravamiento. A las 08:45 hrs presentó paro cardiorrespiratorio del cual no se recuperó, falleciendo.

En la Figura 5 se aprecia cronología de la enfermedad en los pacientes de ambos grupos familiares.

\section{DISCUSION}

La frecuencia del SPH en el niño bajo 15 años de edad, en relación al total de enfermos regionales del período analizado, fue de $15 \%$ (6/41), superior a las cifras de $4 \%$ para este grupo etario en reportes de E.U.A. ${ }^{10-14}$ Es muy probable que esta diferencia se explique por las características de nuestro sector rural, en que las condiciones de la vivienda y la participación infantil en las labores agrícolas es frecuente. Estas situaciones facilitarían el contagio de los niños. El predominio de varones podría ser explicado en parte por estas razones y también por la mayor curiosidad por el entorno geográfico, propia de su género.

No hubo diferencias en el origen étnico de los pacientes; 3 tenían uno o dos apellidos de origen mapuche, con proporción similar a la población regional. La mayor frecuencia manifestada por el SPH en 1998 avala la proyección epidémico-endémico de esta zoonosis probablemente relacionada con cambios climáticos y ecológicos. ${ }^{4}$

La letalidad fue de $33,3 \%$, inferior a la 
letalidad global en población adulta para el país. ${ }^{1,4}$ Aunque el número de pacientes no permite obtener conclusiones definitivas, nuestro reporte favorece la impresión de un curso menos grave de la enfermedad en el niño. Si esta tendencia fuese confirmada, podría tener relación con los mecanismos fisiopatológicos del síndrome. De acuerdo al conocimiento actual, la respuesta del huésped es muy importante en la evolución del cuadro. En esta respuesta, el rol de las citoquinas al actuar en el endotelio vascular, en la pared bronquial y probablemente en el miocardio, desencadenan los mecanismos que llevan a un aumento dramático de permeabilidad vascular, falla cardíaca, shock y muerte. Es probable que por inmadurez de la respuesta inmune, estos mecanismos sean diferentes en el niño lo que explicaría un mejor pronóstico. Esta situación también se aprecia en otras enfermedades de origen viral, en la cuales el curso es más grave en el adulto, como sarampión y varicela entre otras.

Las manifestaciones clínicas en la fase prodrómica, aunque la sintomatología es coincidente con lo señalado en el adulto, tienen algunos aspectos que deben destacarse. La fiebre fue constante y elevada. El dolor abdominal es síntoma y signo mayor, tan intenso que sugirió un cuadro de abdomen agudo en tres pacientes; en los reportes de SPH en adultos no es tan llamativo. Las mialgias, especialmente en extremidades inferiores, también fueron un síntoma destacado.

Fue llamativa también la regularidad de las alteraciones hematológicas, que preceden a la fase pulmonar (leucocitosis, formas inmaduras, linfocitosis). Destaca de este aspecto, el paciente 2 (caso clínico 1) que ingresó por la sospecha clínica de leucemia linfoblástica. No hemos encontrado relato de casos similares en niños. La trombocitopenia acentuada es otro hecho constante y de valor en la sospecha diagnóstica. A pesar de esta plaquetopenia y la prolongación de los tiempos de protrombina y tromboplastina en tres pacientes, sólo en dos se presentaron manifestaciones hemorrágicas como petequias. En los pacientes pediátricos de la XI Región y en otros reportes, se ha descrito con más frecuencia este hallazgo clínico. ${ }^{5}$
El alza de hematocrito es signo de mal pronóstico que estaría revelando gran pérdida transcapilar de líquido. En los casos fatales se encontraron los valores más elevados. Este hecho es de gran valor en la monitorización del paciente crítico.

Las alteraciones de las enzimas hepáticas revelan el compromiso sistémico de la enfermedad por acción directa del agente o posiblemente por mecanismo inmune. ${ }^{15}$

Aunque no se constató en ningún paciente compromiso renal, en todos hubo alteraciones electrolíticas con hiponatremia marcada y potasio sérico en el límite superior. En el paciente 1 hubo poliuria con pérdida importante de sodio en la fase de convalecencia, sin aumento de creatininemia. Estas alteraciones apoyan la hipótesis que señala el SPH como una enfermedad sistémica, pero con mayor compromiso cardiopulmonar. Esta característica lo define y confiere su particular gravedad. ${ }^{13-16}$

La fase pulmonar en cuatro pacientes fue notoria, con sintomatología clínica y expresión radiológica características. Sin embargo, sólo dos de ellos evolucionaron hacia el shock irreversible en pocas horas, en forma similar a los casos fulminantes descritos en adultos; en los otros dos con fase pulmonar evidente, llamó la atención una "tolerancia" clínica discordante con la expresión radiológica. Los restantes dos enfermos presentaron un compromiso respiratorio moderado, aunque la radiografía de tórax mostró en ambos neumonitis intersticial difusa.

La infección por hantavirus fue confirmada serológicamente en todos los pacientes a través de la determinación de IgM e IgG llamando la atención que ya en la fase prodrómica la $\operatorname{IgG}$ fuese positiva en 4 de 6 pacientes, lo que debiera explicarse por un período largo de incubación. Estas técnicas utilizan anticuerpos específicos antivirus Laguna Negra y Virus Sin Nombre, como se señaló anteriormente y tienen una alta sensibilidad y especificidad con identidad genética a virus Andes. ${ }^{2}$

La detección del virus Andes por técnicas de biología molecular en dos pacientes de las regiones IX y X, sin relación epidemiológica familiar, corrobora nuevamente como responsable del síndrome esta cepa viral detectada ini- 
cialmente tanto en humanos como ratones en Argentina y XI Región de Chile. ${ }^{17-18}$

Los brotes o clusters en grupos familiares con más de un enfermo merecen un comentario especial. A partir de la experiencia de los casos de SPH de la región de El Bolsón, Argentina, con una muy documentada confirmación de la transmisión de persona a persona del síndrome, siempre está latente esta posibilidad. ${ }^{19-21}$ En Chile se ha sospechado este comportamiento epidemiológico en grupos familiares. Sin embargo, el estudio de contactos no apoya esta hipótesis. Sólo se sabe que hay enfermedad subclínica. ${ }^{1,3-5}$

En el caso familiar 1 se podría plantear que el contagio fue simultáneo para sobrino y tío, teniendo este último un período de incubación mayor, o bien hubo diferentes fechas de contagio o por último, que hubo transmisión intrafamiliar. La detección del virus en el plasma del tío sólo permite aventurar una carga viral muy grande que pudiese haber influido en la evolución fatal. Se podría plantear la existencia de cepas virales de mayor virulencia, y/o características particulares del huésped humano que facilitaran la transmisión del agente viral.

En el caso familiar 2 la situación es más dramática. Primero falleció el padre y a los 24 días el hijo. Cabe plantearse las mismas interrogantes. Un primer examen serológico negativo en el niño y una posterior seroconversión sugieren que el niño estaba en período de incubación. ¿Existió una fuente similar de contagio?. ¿Hubo transmisión interpersonal con diferentes períodos de incubación?.

En tanto no se conozca más sobre este punto deben tomarse todas las medidas universales de manejo de líquidos biológicos y aislamiento respiratorio en el cuidado de estos pacientes, especialmente en la fase crítica.

Respecto al tratamiento, no existe actualmente un medicamento específico. El uso de corticosteroides pudiera tener un fundamento en la etapa precoz de compromiso respiratorio como inhibidor de la respuesta inflamatoria mediada por citoquinas. ${ }^{3,15}$ Los fármacos antivirales como ribavirina, aún están en etapa de estudio y no hay consenso en su beneficio. ${ }^{22}$ Mientras no se conozcan medidas terapéuticas específicas seguirá siendo importante el diagnóstico oportuno y el manejo monitorizado y agresivo del paciente. El uso juicioso de medicamentos vasoactivos e inotrópicos, el manejo racional de volúmenes y el monitoreo continuo podrán salvar muchas vidas. ${ }^{23-25}$

Es conveniente aprender a convivir con el SPH y evitar esta dramática enfermedad, para ello es fundamental la prevención y la difusión de las medidas correspondientes, tanto para la población rural como el público en general.

\section{RESUMEN}

El síndrome pulmonar por hantavirus (SPH) ha estado presente en Chile desde 1993 y ha sido detectado desde 1997 en la IX Región. Es una grave zoonosis con alta mortalidad, que afecta a gente joven incluyendo niños. Se ha estimado oportuno dar a conocer nuestra experiencia en la atención de 6 pacientes pediátricos, atendidos en las unidades de Cuidados Intensivos y Aislamiento en el Hospital Regional de Temuco, entre enero de 1998 y enero de 2000 mediante un estudio descriptivo de la experiencia del equipo de salud en la atención de estos pacientes. La información clínico-epidemiológica se extrajo de las fichas clínicas y visitas a terreno. Se efectuó la confirmación etiológica por detección de anticuerpos específicos -IgM e IgG- mediante tests de ELISA y la pesquisa de genoma viral por reacción de polimerasa en cadena (TR RPC). Edad promedio 6 años 5 meses (rango: 2-10 años). relación varón/mujer: 4/2. Procedencia: de área rural cordillerana (n: 4), costera (n:2). Todos tuvieron exposición en casas deshabitadas o galpones. Período de incubación promedio: 14 días (rango: 7-21). Todos los pacientes tuvieron fiebre elevada, dolor abdominal intenso, vómitos, mialgias, compromiso respiratorio clínico y radiológico. Hallazgos hematológicos constantes: trombocitopenia, leucocitosis, inmunoblastos o linfocitosis con formas atípicas. La confirmación etiológica (IgM e IgG positivas) se alcanzó en todos. En dos pacientes se detectó en sangre la secuencia genética viral de hantavirus cepa Andes. Dos pacientes en los cuales se requirió ventilación 
mecánica y manejo del shock, finalmente fallecieron; los otros enfermos tuvieron una recuperación rápida. No existe una terapia específica conocida para el SPH, la prevención, una sospecha y diagnóstico oportunos y el tratamiento agresivo son las estrategias actuales para luchar contra esta enfermedad.

\section{BIBLIOGRAFIA}

1.- Ministerio de Salud de Chile. Hantavirus: Situación epidemiológica. http://disap.minsal.cl/epidemiología /enftrans/hanta.htlm

2.- NAVARRETE M, SALDIAS F, MANCILLA R, ZAROR L, FERRES M et al. Evidencia clínicaepidemiológica de síndrome pulmonar por hantavirus en Valdivia-Chile desde 1993. Rev Chil Infect 2000; 17 (3): 233-40.

3.- TAPIA G M. Síndrome Pulmonar por Hantavirus. Rev Chil Enf Respir 1997; 13: 103-10.

4.- Segundo Seminario Internacional de Hantavirus. Valdivia 18, 19 y 20 de Noviembre de 1998. Ministerio de Salud, Junio 1999, Chile.

5.- ESPINOZA M A, LUCERO C, ALVAREZ P et al. Infección por virus Hanta en niños, Hospital Regional de Coyhaique, Chile. XXXVIII Congreso Chileno de Pediatría, Santiago 1999.

6.- PINI N C, RESA A DEL JESUS LUANG G et al. Hantavirus infection in children in Argentina. Emerg Infect Dis 1998; 4 (1): 85-7.

7.- NICHOL S T, SPIROPOULOU C F, MORZUNOV $\mathrm{S}$ et al. Genetic identification of a hantavirus associated with an outbreak of acute respiratory illness. Science 1993; 262: 914.

8.- SPIROPOULOU C F, MORZUNOV S, FELDMANN H et al. Genome structure and variability of a virus causing hantavirus pulmonary syndrome. Virology 1994; 200: 715-23.

9.- LEVIS S C, MORZUNOV S P, ROWE J E et al. Genetic diversity and epidemiology of hantaviruses in Argentina. J Infect Dis 1998; 177: 529-38.

10.- PFLIEGER K A, KHAN S A. Hantaviruses: Four years after Four Corners. Hosp Practice 1997; 5: 98-108.
11.- MERTZ G J, HJELLE B L, BRYAN R T. Hantavirus infection. Adv Intern Med 1997; 42: 369421.

12.- RUCHIN J, KUSTER F, PELES C J et al. Hantavirus pulmonary syndrome: A clinical description of 17 patients with a newly recognized disease. N Engl J Med 1994; 330: 949-55.

13.- KHAN S A, KSIAZEK G T, PETERS C J. Hantavirus pulmonary syndrome. Lancet 1996; 347: 34955.

14.- KHAN S A, KABBAZ F R, ARMSTRONG R C et al. Hantavirus pulmonary syndrome. The first 100 US cases. J Infect Dis 1996; 173: 1297-303.

15.- SEIJO A C. Patogenia. Fisiopatología. Manifestaciones clínicas y tratamiento del Síndrome Pulmonar por Hantavirus. Medicina (Buenos Aires) 1998; 58 (1): 19-24.

16.- Hantavirus Pulmonary Syndrome. Panamá, 19992000. MMWR 2000; 49 (10): 205-7.

17.- ENRIA A D. Emergencia de los Hantavirus en las Américas y en la Argentina. Medicina (Buenos Aires) 1998; 58 (1): 15-8.

18.- LEVIS S. Reservorio y diversidad genética viral. Medicina (Buenos Aires). 1998; 58 (1): 37.

19.- An unusual Hantavirus outbreak in Southern Argentina: Person-to-person transmission. Emerg Infect Dis 1997; 3 (2): 1-9.

20.- ENRIA D, PADULA P, SEGURA E C et al. Hantavirus pulmonary syndrome in Argentina. Possibility of person to person transmission. Medicina (B. Aires). 1996; 56: 709-11.

21.- PADULA J P, EDELSTEIN A, MIGUEL S D et al. Brote epidémico del Síndrome Pulmonar por Hantavirus en la Argentina. Evidencia molecular de la transmisión persona a persona del virus Andes. Medicina (B. Aires) 1998; 58 (Supl 1): 27-36.

22.- HJELLE B. Hantavirus: El uso de ribavirina. Health IG News 1997; 11: 4.

23.- Infección por Virus Hanta: Diagnóstico y Tratamiento. Ministerio de Salud Chile, 1997.

24.- HORWITZ I, THOMPSON L, LUCHSINGER V. et al. Infección por Hantavirus: Orientaciones generales para el diagnóstico y manejo de pacientes hospitalizados por sospecha o confirmación de Síndrome Pulmonar por Hantavirus. Rev Chil Infect 1997; 14: 74-82.

25.- All about Hantavirus: Prevention 1998. The Centers for Disease Control and Prevention (CDC).

Correspondencia a:

Guillermo Soza Contreras

Fax: 56 (45) 325777

E-mail:gsoza@entelchile.net 